\title{
Methylophiopogonanone A suppresses ischemia/ reperfusion-induced myocardial apoptosis in mice via activating PI3K/Akt/eNOS signaling pathway
}

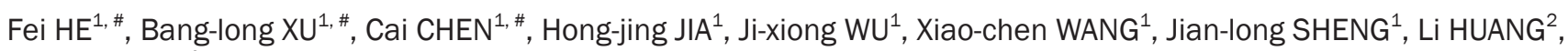 \\ Jing $\mathrm{CHENG}^{2, *}$ \\ ${ }^{1}$ Department of Cardiology, Second Affiliated Hospital of Anhui Medical University, Hefei 230601, China; ${ }^{2}$ School of Nursing, Anhui \\ University of Chinese Medicine, Hefei 230038, China
}

Aim: The dried tuber root of Ophiopogon japonicus has been used in the traditional Chinese medicine for treatment of myocardial ischemia and thrombosis. In this study we investigated the effects of methylophiopogonanone A (MO-A), a major homoisoflavonoid in Ophiopogon japonicus, on myocardial ischemia/reperfusion (I/R) injury.

Methods: Mice were pretreated with MO-A (10 $\left.\mathrm{mg}_{\mathrm{kg}} \cdot \mathrm{d}^{-1}, \mathrm{po}\right)$ for 2 weeks and then subjected to transient occlusion of the left anterior descending coronary artery. Cardiac function was evaluated, and the infarct size and apoptosis index were assessed. The mechanisms underlying the cardio-protection of MO-A were analyzed in H9C2 rat cardiomyocytes subjected to hypoxia/reoxygenation (H/R). The cell viability and apoptosis were evaluated; apoptotic and relevant signaling proteins were analyzed. NO levels in the culture medium were assessed.

Results: In I/R mice, pretreatment with MO-A significantly reduced the infarct size (by 60.7\%) and myocardial apoptosis (by 56.8\%), and improved cardiac function. In H9C2 cells subjected to H/R, pretreatment with MO-A (10 $\mu$ mol/L) significantly decreased apoptosis and cleaved caspase- 3 expression, elevated the Bcl-2/Bax ratio and restored NO production. Furthermore, pretreatment with MO-A markedly increased the activation of PI3K/Akt/eNOS pathway in $\mathrm{H} 9 \mathrm{C} 2$ cells subjected to $\mathrm{H} / \mathrm{R}$, and the protective effects of MO-A were abolished in the presence of the PI3K inhibitor wortmannin (100 nmol/L).

Conclusion: MO-A attenuates I/R-induced myocardial apoptosis in mice via activating the PI3K/Akt/eNOS signaling pathway.

Keywords: coronary heart disease; ischemia/reperfusion; H9C2 rat cardiomyocytes; apoptosis; PI3K/Akt; eNOS; methylophiopogonanone A; wortmannin; cardio-protection

Acta Pharmacologica Sinica (2016) 37: 763-771; doi: 10.1038/aps.2016.14; published online 11 Apr 2016

\section{Introduction}

Coronary heart disease (CHD) is one of the leading causes of death worldwide. Acute myocardial infarction (AMI) is the most severe and fatal subtype of CHD. Although timely and successful myocardial reperfusion is the most effective strategy to reduce the infarct size and to improve the clinical outcome after an AMI, the process of restoring blood flow to the ischemic myocardium can also induce injury ${ }^{[1]}$. This phenomenon, termed myocardial ischemia/reperfusion (I/R) injury, can paradoxically reduce the beneficial effects of myocardial reperfusion $^{[2]}$. In recent years, enormous efforts have

\footnotetext{
\# These authors contributed equally to this work.

* To whom correspondence should be addressed.

E-mail jingcheng3344@foxmail.com

Received 2015-10-02 Accepted 2016-02-06
}

been made to explore approaches to protect the myocardium against I/R injury ${ }^{[3,4]}$. However, few effective methods are available to prevent reperfusion injury. Further studies are needed to seek novel strategies and targets to reduce myocardial ischemia/reperfusion (I/R)-induced injury.

Recent attention focuses on a series of natural products with the ability to protect the myocardium against I/R injury. The dried tuber root of Ophiopogon japonicus from Ophiopogon japonicus plants is one of the common traditional Chinese medicines used in the clinic, and it has been used for the treatment of myocardial ischemia and thrombosis to remedy hypoxia for many years ${ }^{[5]}$. Homoisoflavonoids were identified in Ophiopogon japonicus, and methylophiopogonanone A (MO-A) is the major contributor to the total homoisoflavonoid content. Previous pharmacological investigations revealed that $\mathrm{MO}-\mathrm{A}$ has both anti-oxidative and anti-inflammatory properties ${ }^{[6]}$. 
However, to the best of our knowledge, there are no reports regarding the effect of MO-A on myocardial I/R injury.

It has been widely accepted that activation of PI3K/Akt signaling exerts cardioprotection against I/R injury by initiating an anti-apoptosis pathway ${ }^{[4,7-9]}$. The present study is designed to investigate whether MO-A exerts cardio-protective effects during myocardial I/R injury in mice by enhancing the PI3K/ Akt pathway.

\section{Materials and methods Animals}

Thirty adult male wild-type C57 BL/ 6 mice (10-12 weeks old; $26-30 \mathrm{~g}$ ) were provided by the Anhui Medical University Laboratory Animal Center (SCXK 2006-0015). All animals used in the present study received ethical and humane care. Experimental procedures were conducted in compliance with the National Institutes of Health Guidelines for Care and Use of Laboratory Animals and were approved by the Bioethics Committees of both Anhui University of Chinese Medicine and Anhui Medical University.

\section{Myocardial I/R model}

The mice were fed either saline or MO-A (Ronghe Technology Co Ltd, Shanghai, China, dissolved in normal saline with $\mathrm{pH}=8.0)$ at doses of $5 \mathrm{mg} / \mathrm{kg}$ twice per day for 2 weeks. After administration with either saline or MO-A, myocardial I/R was produced as described previously ${ }^{[10]}$. In brief, mice were anesthetized with an intra-peritoneal injection of a mixture of xylazine $(5 \mathrm{mg} / \mathrm{kg})$ and ketamine $(100 \mathrm{mg} / \mathrm{kg})$. The left anterior descending (LAD) branch of the coronary artery was occluded using an 8-0 silk suture tied transiently over PE-10 tubing for $1 \mathrm{~h}$. To establish reperfusion, the knot on the PE-10 tubing was cut. Successful reperfusion was determined by recovery of the elevated ST segment. Sham-operated mice underwent the same surgical procedures with the exception of left anterior descending coronary artery occlusion. There were three groups: (1) Sham group; (2) I/R group; and (3) I/R + MO-A $10 \mathrm{mg} \cdot \mathrm{kg}^{-1} \cdot \mathrm{d}^{-1}$ group ( $n=10$ in each group).

\section{Measurement of myocardial infarct size in I/R hearts.}

Evans blue and 2,3,5-triphenyltetrazolium chloride (TTC) were obtained from Sigma-Aldrich (St Louis, MO, USA). Following $24 \mathrm{~h}$ reperfusion, myocardial infarct size was evaluated using Evans blue/TTC dye as previously described ${ }^{[11]}$. The area of infarct size (INF) and area-at-risk (AAR) were measured digitally using Image J software. The INF and AAR were expressed as percentages of the left ventricular area (INF/LV and $\mathrm{AAR} / \mathrm{LV}$, respectively).

\section{Assessment of apoptotic cell death in $\mathrm{I} / \mathrm{R}$ hearts}

Myocardial apoptosis was analyzed using the terminal deoxynucleotidyl transferase-mediated dUTP nick-end labeling (TUNEL) technique and further counterstained with hematoxylin ${ }^{[12]}$. Briefly, $50 \mu \mathrm{L}$ of TUNEL reaction mixture was added to the samples, and the slides were incubated in a humidified atmosphere for $60 \mathrm{~min}$ at $37^{\circ} \mathrm{C}$ in the dark and then rinsed with PBS (pH 7.4) three times for 5 min. The myocardial apoptotic index was calculated as the percentage of TUNELpositive nuclei per 1000 total nuclei in the infarcted border region in 10 random high power fields (HPFs) per mouse.

\section{Cardiac functional analyses by echocardiography and hemo-} dynamic measurements

A Doppler echocardiography was performed before and $72 \mathrm{~h}$ after reperfusion using the Vevo2100 imaging system (VisualSonics, Toronto, Canada) as previously reported ${ }^{[13]}$. In brief, mice received continuously inhaled anesthetic $(1 \%)$ and were maintained at a constant temperature of $37^{\circ} \mathrm{C}$ using a heating pad, and then M-mode echocardiograms were carried out along the short axis of the LV at the level of the papillary muscles during at least three consecutive beats. All measurements were performed in a double-blind manner by two independent researchers.

\section{Exposure of $\mathrm{H} 9 \mathrm{C} 2$ cells to hypoxia-reoxygenation (H/R)}

H9C2 cells were purchased from ATCC (Manassas, VA, USA), seeded at a constant density $\left(10000 / \mathrm{cm}^{2}\right)$ and grown to $80 \%$ confluence in DMEM containing 10\% fetal bovine serum and antibiotics. The cells were washed with HBSS and rendered quiescent in serum-free DMEM for $24 \mathrm{~h}$ prior to the experiments. To further evaluate the cardio-protective effect of MO-A in vitro, $\mathrm{H} 9 \mathrm{C} 2$ cells were treated with either phosphatebuffered saline (PBS) or MO-A (10 $\mu \mathrm{mol} / \mathrm{L}$, dissolved in PBS) before hypoxia for $48 \mathrm{~h}$. To mimic the in vivo I/R model, $\mathrm{H} 9 \mathrm{C} 2$ cells at $80 \%$ confluence were incubated with a glucosefree medium (previously bubbled with a gas mixture containing $95 \% \mathrm{~N}_{2}$ and $5 \% \mathrm{CO}_{2}$ ) for $6 \mathrm{~h}$ at $37^{\circ} \mathrm{C}^{[14]}$. Then, the cells were provided fresh medium and moved to $95 \% \mathrm{O}_{2} / 5 \% \mathrm{CO}_{2}$ for reoxygenation. The control plates were kept in the incubator with $95 \% \mathrm{O}_{2} / 5 \% \mathrm{CO}_{2}$ at $37^{\circ} \mathrm{C}$. The cells were harvested $16 \mathrm{~h}$ post-reoxygenation for further analyses.

\section{Assessment of apoptotic cell death in cultured H9C2 cells}

Fluorescein isothiocyanate (FITC)-conjugated Annexin V and propidium iodide (PI) (Dead Cell Apoptosis Kit with Annexin V FITC and PI for flow cytometry, Thermo Fisher Scientific, Shanghai, China) were used to identify apoptotic cells ${ }^{[14]}$. This assay discriminates between intact $\left(\mathrm{FITC}^{-} / \mathrm{PI}^{-}\right)$and apoptotic $\left(\mathrm{FITC}^{+} / \mathrm{PI}^{-}\right.$and $\mathrm{FITC}^{+} / \mathrm{PI}^{+}$) cells. Comparative experiments were performed at the same time by bivariate flow cytometry using a FACScan (BD) and analyzed with CellQuest (BD Biosciences, Franklin Lakes, NJ) software on data obtained from the cell population.

\section{Cell viability assay of cultured $\mathrm{H} 9 \mathrm{C} 2$ cells}

Cell viability was assessed using the methylthiotetrazole (MTT) assay kit (Beyotime, China) according to the manufacturer's instructions ${ }^{[15]}$. Briefly, the cells were cultured in a 96-well plate at a density of $1 \times 10^{4}$ cells/well and incubated for $24 \mathrm{~h}$. The cells were then pre-treated with or without MO-A $(10 \mu \mathrm{mol} / \mathrm{L})$ for $3 \mathrm{~h}$ at $37^{\circ} \mathrm{C}$. Then, fresh medium and MTT solution $(20 \mu \mathrm{L}$ out of $5 \mathrm{mg} / \mathrm{mL})$ were added to the cells for 
$4 \mathrm{~h}$ followed by incubation with formazan solution $(10 \mu \mathrm{L})$ for $4 \mathrm{~h}$ at $37^{\circ} \mathrm{C}$. The optical density $(O D)$ values at $570 \mathrm{~nm}$ were measured using a Synergy2 microplate reader (Biotek Instruments, Winooksi, VT). Each experiment was repeated 6 times, and the data are expressed as a percentage of the control.

\section{Measurement of NO production in culture medium}

The production of $\mathrm{NO}$ was measured as the generation of nitrite, the stable metabolite of $\mathrm{NO}$, in culture supernatants by the nitrate reductase method using an NO assay kit (Nanjing Jiancheng Institute of Biological Engineering, Nanjing, China). NO levels were expressed as $\mu \mathrm{mol} / \mathrm{L}$.

\section{Western blot analyses}

Cultured cells were lysed in lysis buffer on ice for $30 \mathrm{~min}$, and the lysates were clarified by centrifugation at $4{ }^{\circ} \mathrm{C}$ for $20 \mathrm{~min}$ at $17709 \times g$. After quantitation of protein concentration, total protein was separated by $10 \%$ SDS-PAGE and then transferred to nitrocellulose membranes (Millipore, USA). The membranes were blocked for $30 \mathrm{~min}$ at $37^{\circ} \mathrm{C}$ with $5 \%$ non-fat dry milk, then incubated with primary antibodies including Bcl-2, Bax, caspase-3, $\beta$-actin, PI3K, p-Akt (Ser $\left.{ }^{473}\right)$, Akt, p-eNOS $\left(\operatorname{Ser}^{1177}\right)$, and eNOS (Cell Signaling Technology, USA) (1:1000) overnight (for more than $16 \mathrm{~h}$ ) at $4{ }^{\circ} \mathrm{C}$. After washing with
TBST three times, the membranes were incubated with secondary antibody in TBST solution for $30 \mathrm{~min}$ at $37^{\circ} \mathrm{C}$ and then washed as described above. The positive protein bands were developed using a chemiluminescent system, and the bands were scanned and quantified by densitometry analysis using an image analyzer Quantity One System (Bio-Rad, Richmond, CA, USA).

\section{Statistical analyses}

All measurements are expressed as the mean \pm SEM. The differences between groups were analyzed with one-way ANOVA followed by Student-Newman-Keuls post hoc analysis for pair-wise comparisons. $P<0.05$ was considered statistically significant.

\section{Results}

MO-A reduces infarct size and inhibits cardiomyocyte apoptosis following myocardial $\mathrm{I} / \mathrm{R}$ injury in mice

To examine the effect of MO-A on the infarct size following myocardial I/R, the myocardial infarct sizes of mice in each group were determined by TTC/Evans blue dye $24 \mathrm{~h}$ after reperfusion. The representative mid-ventricular cross-sections are shown in Figure 1A ( $n=10$ in each group). Mice pre-treated with MO-A displayed much smaller INF/LV $(10.1 \% \pm 2.1 \%)$
A

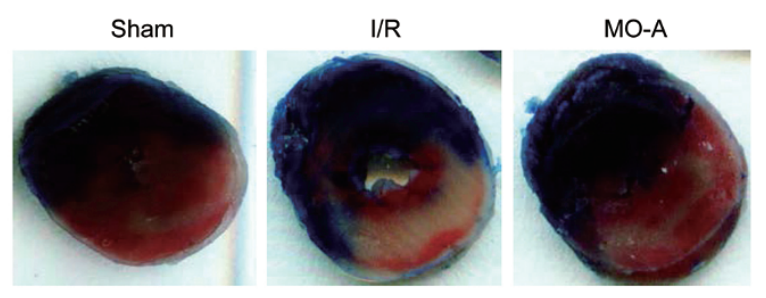

C

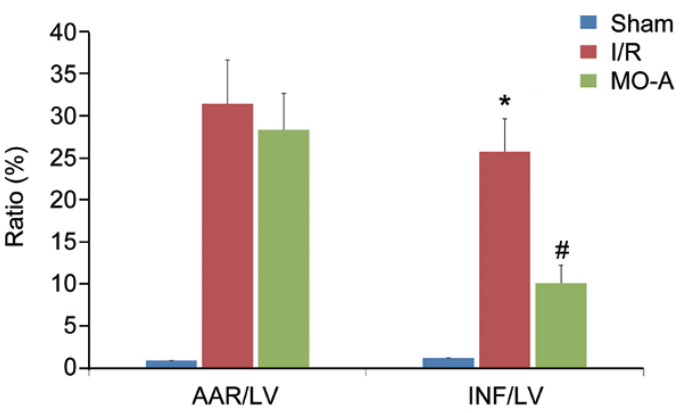

B

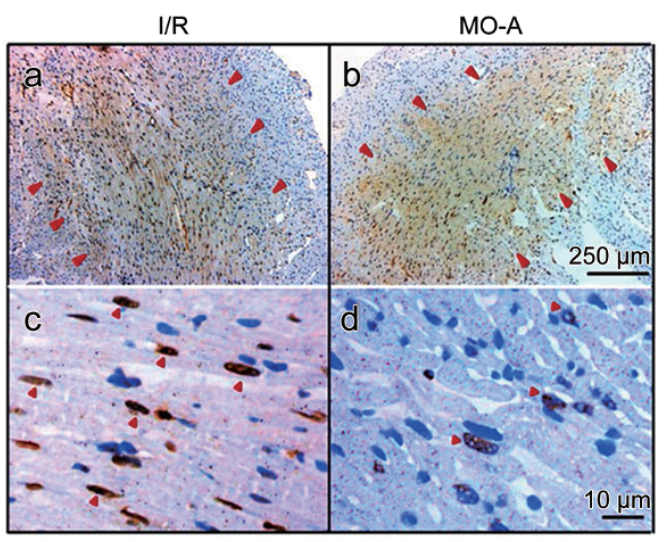

D

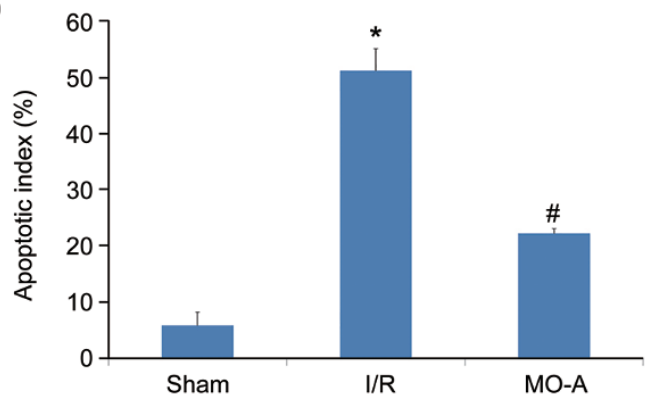

Figure 1. MO-A reduced infarct size and apoptosis following myocardial I/R in mice. (A) Representative photomicrographs of TTC/Evan blue staining in heart tissues from mice in sham, I/R, and I/R+MO-A pretreatment group. (B) Representative micrographs of left mid-ventricular sections with TUNEL staining (arrows indicate TUNEL-positive nuclei). (C) MO-A reduced infarct size following myocardial I/R in mice. (D)MO-A inhibited apoptosis following myocardial I/R in mice. Values presented are mean \pm SEM. $n=10$ in each group. ${ }^{*} P<0.05$ vs sham operation. ${ }^{\#} P<0.05$ vs $\mathrm{I} / \mathrm{R}$ group. 
compared to I/ R model mice $(25.7 \% \pm 3.9 \%, P<0.01$, Figure $1 C)$, suggesting that treatment of MO-A significantly reduced the infarct size by $60.7 \%$. Moreover, both groups displayed similar AAR/LV percentages $(28.3 \% \pm 4.3 \%$ in the MO-A group vs $31.4 \% \pm 5.2 \%$ in the I/R group, $P=0.347$, Figure $1 C$ ).

Myocardial apoptosis plays a central role in myocardial I/R injury. We examined the effect of MO-A on myocardial apoptosis following I/R injury using TUNEL. The TUNEL-positive cells in the myocardial slices from mice are shown in Figure 1B ( $n=10$ in each group). There was a significantly lower apoptotic index in the MO-A-treated mice $(22.1 \% \pm 2.8 \%)$ than in the I/R model mice $(51.1 \% \pm 5.8 \%, P<0.01$, Figure $1 D)$, suggesting that MO-A significantly decreased myocardial apoptosis by $56.8 \%$.

\section{MO-A protected cardiac function following myocardial I/R injury}

The mice were subjected to Doppler echocardiography $72 \mathrm{~h}$ after the reperfusion to determine the effect of MO-A on the cardiac function ( $n=10$ in each group). The analysis revealed that the left ventricle $(\mathrm{LV})$ ejection fraction $(\mathrm{EF})$ and the fractional shortening (FS) in the MO-A group $(62.1 \% \pm 4.1 \%$ and $41.6 \% \pm 1.8 \%$, respectively) following $72 \mathrm{~h}$ reperfusion were significantly higher than those in the I/R group $(43.9 \% \pm 5.8 \%$ and $26.6 \% \pm 1.5 \%$, respectively, Figure $2 \mathrm{~A}-2 \mathrm{C}$ ). In addition, MO-A pretreatment resulted in a significant improvement in systolic dysfunction, which manifested as the maximal velocity of left ventricular pressure development $(+\mathrm{d} p / \mathrm{d} t)(11329 \pm 420.1$ vs $9512 \pm 390.6 \mathrm{mmHg} / \mathrm{s}, P<0.05$, Figure $2 \mathrm{D}$ ) as well as decreased left ventricular end-diastolic pressure (LVEDP) $(10.13 \pm 1.129$ vs $14.266 \pm 1.191 \mathrm{mmHg}, P<0.05$, Figure $2 \mathrm{E})$ and increased left ventricular systolic pressure (LVSP) (108.2 \pm 4.215 vs $96.3 \pm 3.189$ $\mathrm{mmHg}, P<0.05$, Figure $2 \mathrm{~F}$ ). All of these parameters were similar in both groups before I/R, suggesting that MO-A itself had no influence on LV function.
MO-A decreased apoptosis, increased cell viability and exerted anti-oxidant effects following $\mathrm{H} / \mathrm{R}$ in $\mathrm{H} 9 \mathrm{C} 2$ cells

To establish the in vitro H/R injury model, the H9C2 cells underwent hypoxia for $3 \mathrm{~h}$ followed by reoxygenation for $16 \mathrm{~h}$. The validity of the in vitro model was evaluated by flow cytometry using Annexin V/PI double staining. The result showed that the apoptotic index in the H/R injury group was significantly higher than that in the control group $(39.71 \% \pm 3.37 \%$ vs $5.05 \% \pm 1.29 \%$, respectively, $P<0.01$, Figure $3 \mathrm{~A}-3 \mathrm{~B}, n=6$ in each group). In addition, there was no significant difference between the apoptotic rate of the control group and that of the MO-A alone group $(5.05 \% \pm 1.29 \%$ vs $4.34 \% \pm 1.01 \%$, respectively, $P=0.43$, Figure $3 \mathrm{~A}, 3 \mathrm{~B}$ ). Furthermore, MO-A pretreatment before $\mathrm{H} / \mathrm{R}$ decreased the apoptosis rate compared to that of the cells that underwent $\mathrm{H} / \mathrm{R}$ alone $(39.71 \% \pm 3.37 \%$ vs $15.09 \% \pm 1.33 \%$, respectively, $P<0.01$, Figure $3 \mathrm{~A}, 3 \mathrm{~B})$. Additionally, MO-A pretreatment before $H / R$ preserved cell viability compared to that of the cells that underwent $\mathrm{H} / \mathrm{R}$ alone $(54.8 \% \pm 9.4 \%$ vs $78.2 \% \pm 11.4 \%$, respectively, $P<0.01$, Figure 3C).

\section{MO-A treatment activated PI3K-Akt-eNOS and restored NO production}

To investigate the mechanisms underlying the cardioprotective effects of MO-A, we investigated the expression of PI3K, phosphor-Akt $\left(\mathrm{Ser}^{473}\right)$, and phosphor-eNOS $\left(\mathrm{Ser}^{1777}\right)$ in vitro. After H/R, the phosphorylation levels of PI3K, Akt, and eNOS decreased 5-fold, 4.76-fold, and 9.09-fold, respectively, compared with those of the control group $(P<0.05$, Figure 4$)$. MO-A pretreatment resulted in markedly increased expression of PI3K (8-fold), p-Akt (3.9-fold), and p-eNOS (6.55-fold) compared with the H/R group $(P<0.05$, Figure 4$)$.

To further determine the effect of MO-A on NO production, the levels of NO in the culture medium were measured.
A

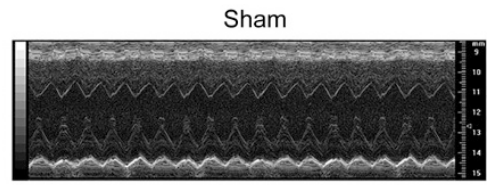

$1 / R$

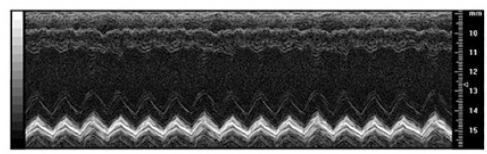

MO-A

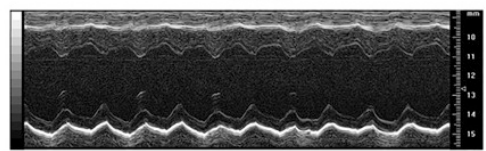

B

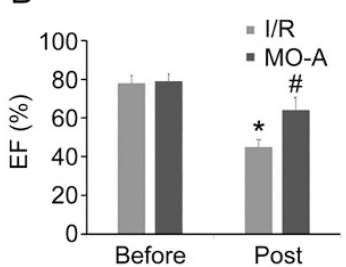

C

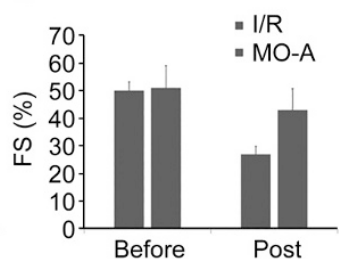

D

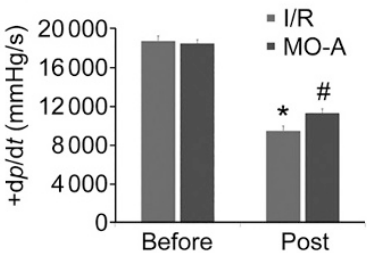

$\mathrm{E}$

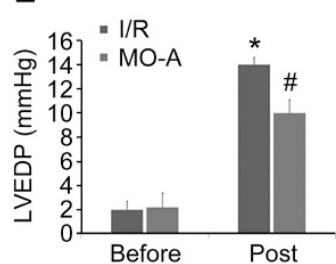

F

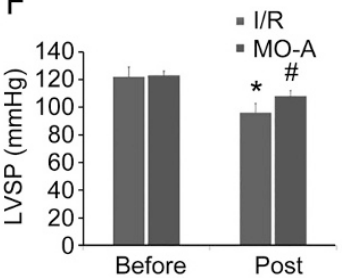

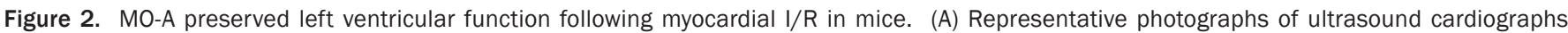

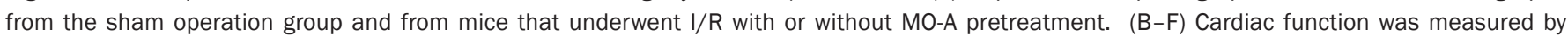

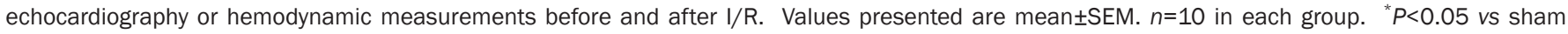

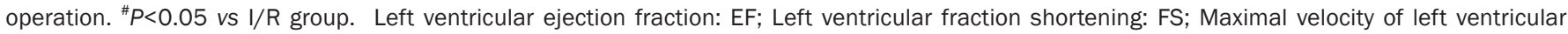
pressure development: $+\mathrm{d} p / \mathrm{d} t$; Left ventricular end-diastolic pressure: LVEDP; Left ventricular systolic pressure: LVSP. 
A

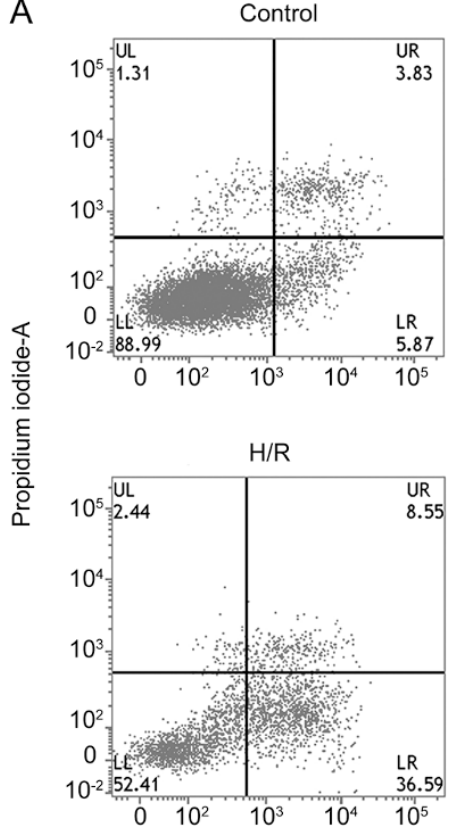

MO-A
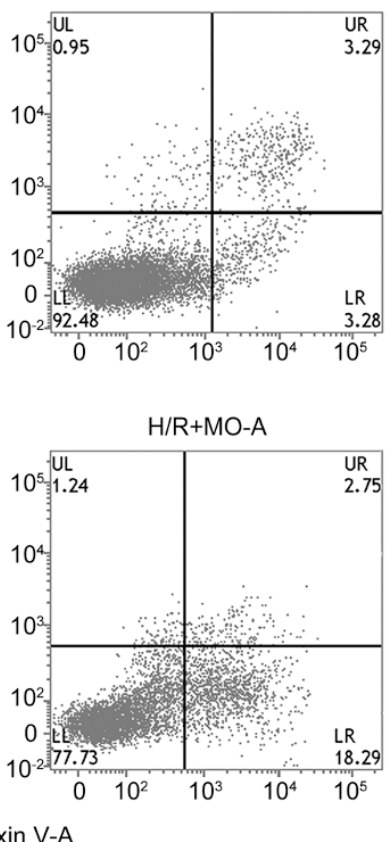

B

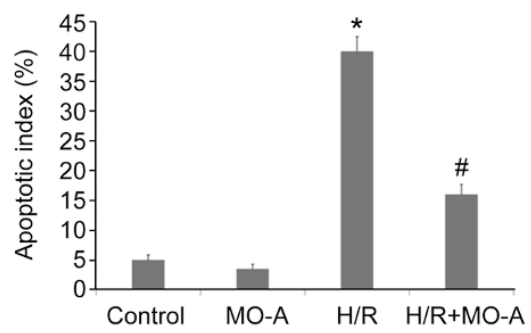

C

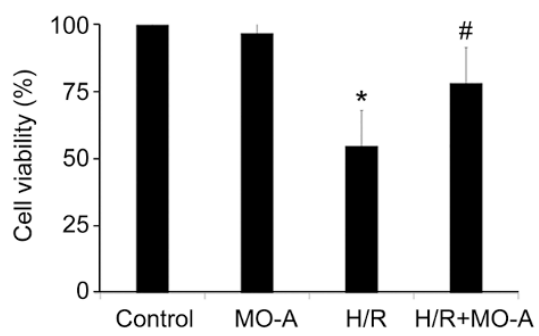

Figure 3. Assessment of apoptotic cell death and cell viability in cultured $\mathrm{H} 9 \mathrm{C} 2$ cells. (A) Flow cytometry revealed that MO-A alleviated H/R-induced apoptosis of $\mathrm{H} 9 \mathrm{C} 2$. The lower right (LR) region shows the early apoptotic cells ( $\mathrm{FITC}^{+} / \mathrm{PI}$ ). (B) MO-A decreased H/R-induced apoptosis of H9C2 cells. (C) MO-A increased cell viability after $\mathrm{H} / \mathrm{R}$ treatment. Values presented are mean \pm SEM. $n=6$ in each group. ${ }^{*} P<0.05$ vs sham operation. ${ }^{\#} P<0.05$ vs $H / R$ group.

A

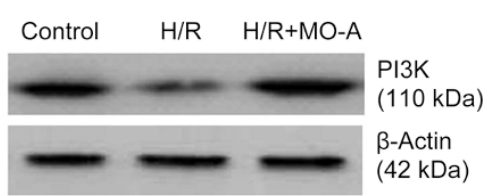

B
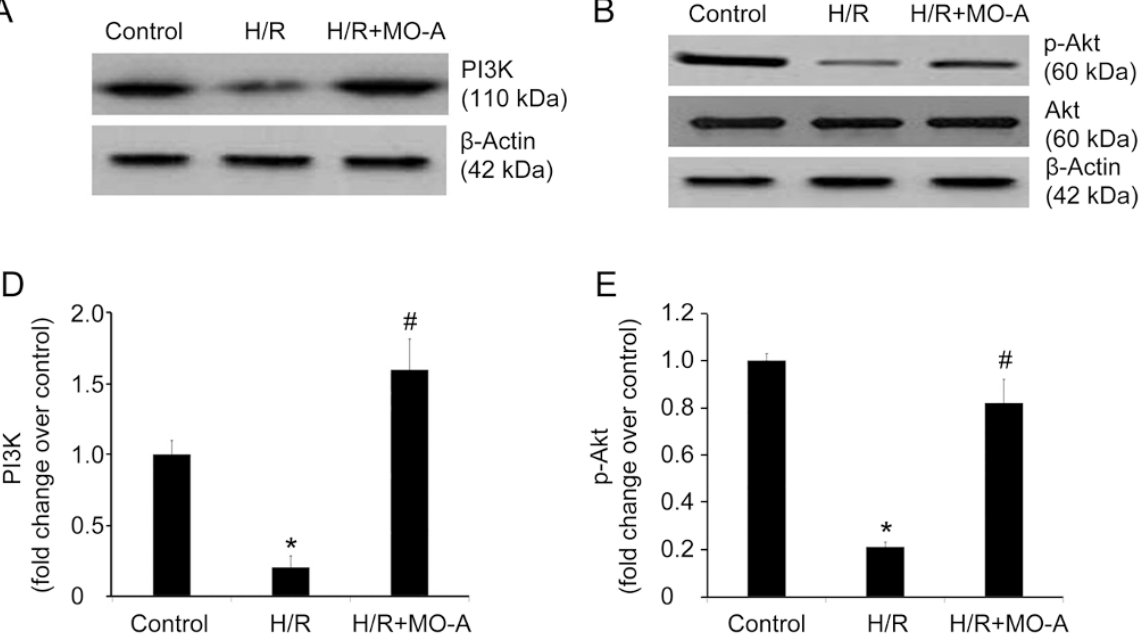

$\mathrm{E}$

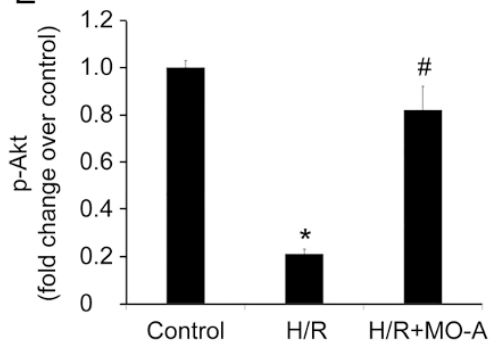

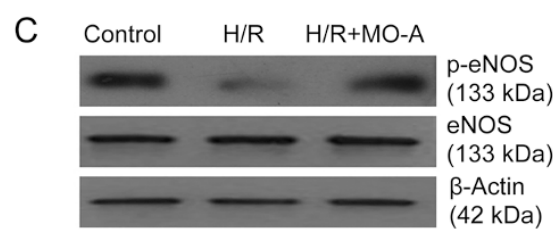

$\mathrm{F}$

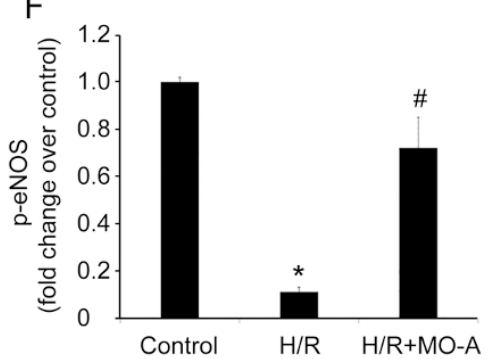

Figure 4. MO-A activated the PI3K-Akt-eNOS pathway in H9C2 cells exposed to H/R. (A) Ratio of PI3K/ 3 -actin. (B) Ratio of phosphorylated Akt/total Akt; and (C) ratio of phosphorylated eNOS/total eNOS. (D-F) p-Akt, p-eNOS and PI3K levels were normalized by Akt, eNOS and $\beta$-actin, respectively, and expressed as fold of the H/R group. Values presented are mean \pm SEM. $n=6$ in each group. ${ }^{*} P<0.05$ vs sham operation. ${ }^{\#} P<0.05$ vs $H / R$ group.

As shown in Figure 5A, NO production was significantly decreased in the H/R group $(148.65 \pm 18.32 \mu \mathrm{mol} / \mathrm{L})$ compared with that in the control group $(322.84 \pm 29.33 \mu \mathrm{mol} / \mathrm{L}, P<0.01)$. $\mathrm{MO}-\mathrm{A}$ at a dose of $10 \mu \mathrm{mol} / \mathrm{L}$ restored NO production $(237.39 \pm 20.84 \mu \mathrm{mol} / \mathrm{L})$, which was significantly higher compared with the H/R group $(148.65 \pm 18.32 \mu \mathrm{mol} / \mathrm{L}, P<0.01)$.
MO-A increased the Bcl-2/Bax ratio and decreased cleaved caspase-3 expression

As Bcl-2, Bax and caspase- 3 are thought to play major roles in the determination of cell survival or death after apoptotic stimuli, their expression levels in $\mathrm{H} 9 \mathrm{C} 2$ cells were determined to examine the mechanism by which MO-A decreases apop- 

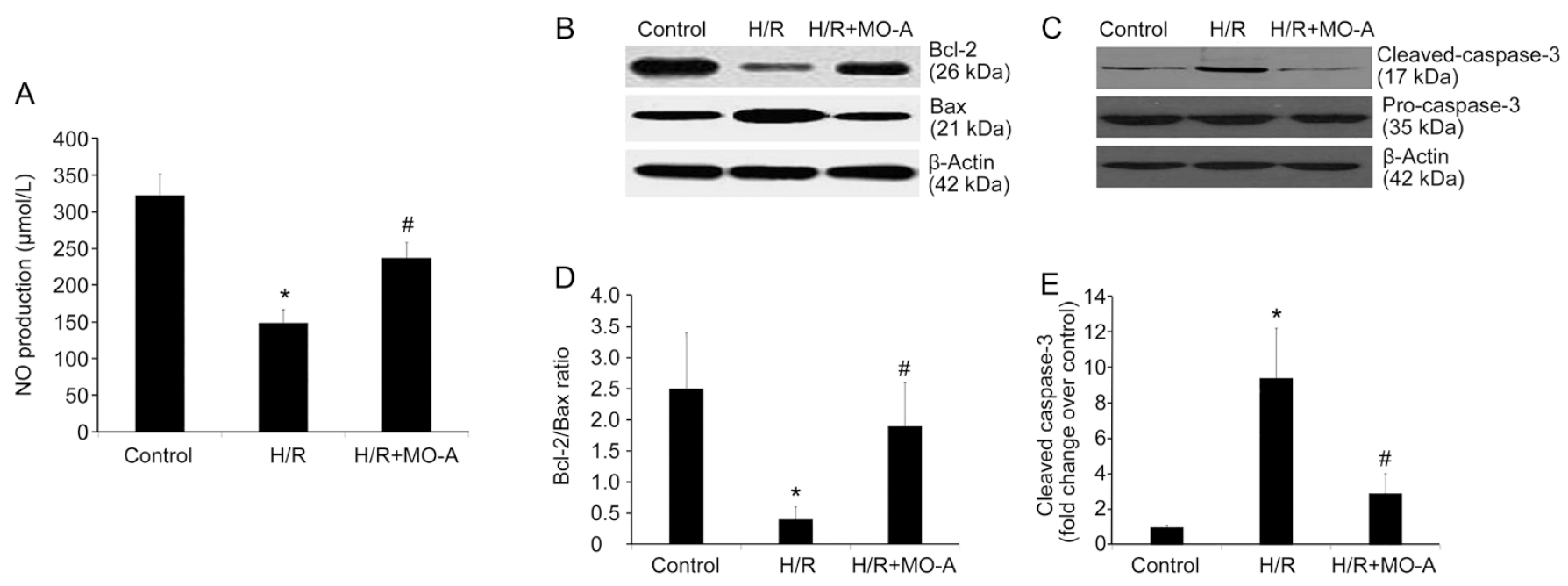

Figure 5. MO-A restored NO production, increased Bcl-2/Bax ratio and decreased cleaved caspase-3 in H9C2 cells exposed to H/R. (A) MO-A restored NO production in $\mathrm{H} 9 \mathrm{C} 2$ cells exposed to H/R. (B) The protein levels of $\mathrm{Bcl}-2$ and Bax and the ratio of Bcl-2/Bax. (C) The protein levels of cleaved caspase-3 and the ratio of cleaved caspase-3/B-actin. (D-E) Quantitative analysis of $\mathrm{Bcl}-2 / \mathrm{Bax}$ and cleaved caspase 3 . Values presented are mean \pm SEM. $n=6$ in each group. ${ }^{*} P<0.05$ vs sham operation. ${ }^{\#} P<0.05$ vs $H / R$ group.

tosis. The Bcl-2/Bax ratio was significantly decreased in the $\mathrm{H} / \mathrm{R}$ group (0.16-fold in $\mathrm{H} / \mathrm{R}$ group ws the control group, $P<0.01$, Figure 5B). However, $\mathrm{MO}-\mathrm{A}$ pretreatment resulted in a noticeable increase in the Bcl-2/Bax ratio compared with that of the H/R group (4.75-fold os the H/R group, $P<0.01$ ). As illustrated in Figure 5C, the expression of cleaved caspase-3 significantly increased in H9C2 cells that underwent H/R (9.4-fold $v$ s the control group, $P<0.01)$, and this increase was blocked by MO-A pretreatment (0.31-fold vs the H/R group, $P<0.01)$.

Inhibition of the PI3K-Akt pathway partly abolished the cardioprotective effect of MO-A pretreatment

To further confirm the underlying mechanism of the cardioprotective effects of MO-A, wortmannin (W, $100 \mathrm{nmol} / \mathrm{L}$ ), a PI3K-Akt inhibitor, was administered $10 \mathrm{~min}$ before MO-A pretreatment. We found that the anti-apoptotic effects of $\mathrm{MO}-\mathrm{A}$ on H9C2 cells were attenuated in the presence of wortmannin $(24.86 \% \pm 4.0 \%, P<0.05$ compared with the $\mathrm{H} / \mathrm{R}+\mathrm{MO}-$ A group, Figure 6C and 6D). Moreover, compared with the $\mathrm{MO}-\mathrm{A}$ pretreatment group, cell viability was impaired in the wortmannin group $(59.6 \% \pm 7.1 \%$ vs $79.3 \% \pm 8.2 \%$, respectively, $P<0.05$, Figure 6E), suggesting that blockade of PI3K-Akt inhibited the anti-apoptotic effects of MO-A on H9C2 cells. Moreover, the restoration of $\mathrm{NO}$ production after MO-A pretreatment was partly abolished by the administration of wortmannin $(184.82 \pm 17.91 \mu \mathrm{mol} / \mathrm{L}$ vs $237.39 \pm 20.84 \mu \mathrm{mol} / \mathrm{L}, P<0.05$, Figure 6F).

We next determined whether administration of wortmannin could alter the effects of MO-A on the expression levels of p-Akt, p-eNOS and apoptotic proteins. The results showed that co-treatment of wortmannin blocked the Akt (4.42-fold in the MO-A group os 1.94-fold in the wortmannin group, $P<0.05$, Figure 7A)/eNOS (6.22-fold in the MO-A group vs 2.72-fold in the wortmannin group, $P<0.05$, Figure 7B) activation induced by MO-A. Moreover, the increase in the Bcl-2/ Bax ratio by $\mathrm{MO}-\mathrm{A}$ pretreatment was blocked by administration of wortmannin (12.8-fold in the MO-A group vs 2.8-fold in the wortmannin group, $P<0.05$, Figure $7 C)$. Furthermore, as illustrated in Figure 7D, administration of wortmannin resulted in a noticeable increase in cleaved caspase- 3 expression (0.19-fold). In conclusion, the above results demonstrate that MO-A might reduce apoptosis following $\mathrm{H} / \mathrm{R}$ partly by activating PI3K-Akt-eNOS signaling.

\section{Discussion}

In the present study, we found that MO-A protected the heart against I/ $\mathrm{R}$ injury in mice as evidenced by significantly reduced myocardial apoptosis and preserved cardiac function. The in vitro study then revealed that MO-A attenuated $\mathrm{H} / \mathrm{R}$-induced apoptosis of H9C2 cardiomyocytes by activating the PI3K-Akt-eNOS pathway and restoring NO production, thereby altering the expression levels of apoptosis-related proteins including $\mathrm{Bcl}-2$, Bax and caspase-3. These results suggested the therapeutic potential of MO-A for myocardial I/ R injury.

Previous studies reported that a Chinese patent drug consisting of Ophiopogon japonicus (Shengmai San) might significantly protect the brain against I/ $\mathrm{R}$ injury ${ }^{[16,17]}$, and $\mathrm{MO}-\mathrm{A}$ is one of the major isoflavonoids present in Ophiopogon japonicus $^{[17]}$. In the present study, we found that MO-A significantly reduced infarct size as illustrated by TTC/Evans blue staining after I/ R injury in mice. We also demonstrated that MO-A treatment for two weeks resulted in significant recovery of cardiac function in mice suffering from I/R, suggesting that MO-A exerts a protective effect against myocardial I/ R injury.

The pathogenesis of reperfusion-induced myocardial injury is apparently multi-factorial, and apoptosis is one of the major 
A
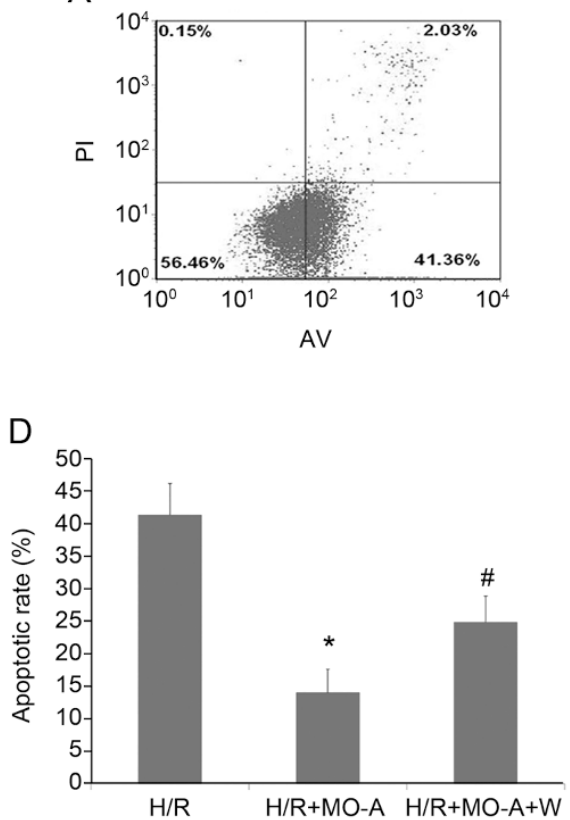

B

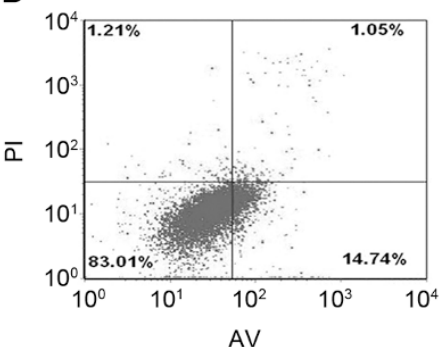

E

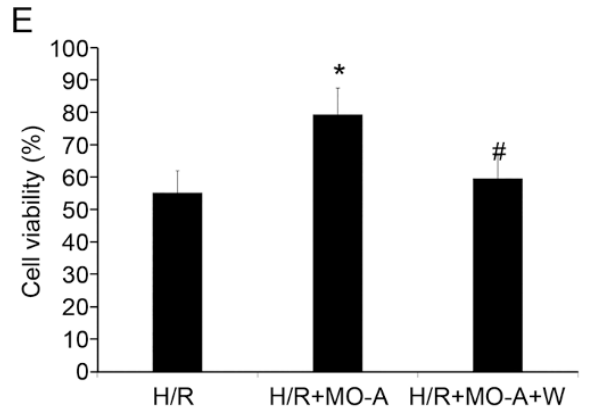

C

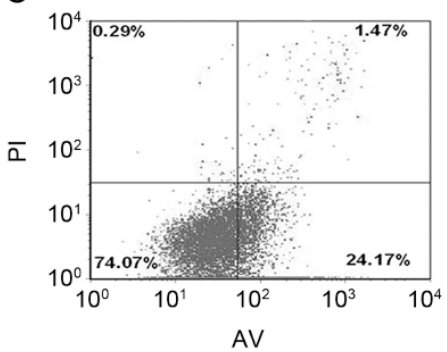

F

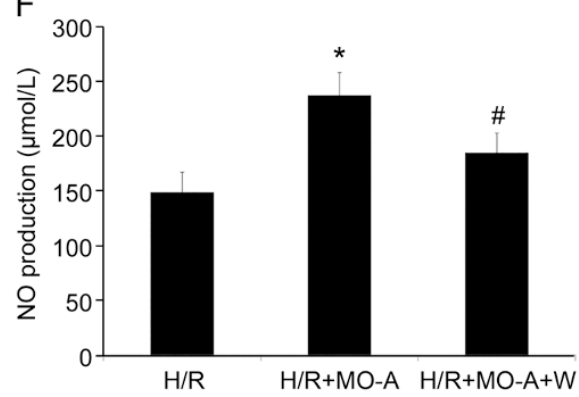

Figure 6. Effects of MO-A on apoptosis, cell viability and NO production were blocked by the PI3K/Akt inhibitor wortmannin. (A) Apoptosis rate of H9C2 cells after H/R determined by flow cytometry. (B) MO-A significantly reduced the apoptosis rate of H9C2 cells after H/R. (C) The anti-apoptotic effect of MO-A was blocked by co-treatment with the PI3K/Akt inhibitor wortmannin. (D-E) The effect of MO-A on cell viability was blocked by the PI3K/Akt inhibitor wortmannin. (F) The effect of MO-A on NO production was blocked by the PI3K/Akt inhibitor wortmannin. Values presented are mean \pm SEM. $n=6$ in each group. ${ }^{*} P<0.05$ vs $\mathrm{H} / \mathrm{R}$ group. ${ }^{\#} P<0.05$ vs H/R+MO-A group.

pathogenic mechanisms underlying I/R injury ${ }^{[18-20]}$. Previous in vivo and in vitro studies have demonstrated that blockade of apoptosis could effectively decrease the loss of contractile cells, minimize I/R-induced myocardial injury and, therefore, slowdown or even prevent the occurrence of heart failure ${ }^{[7,21,22]}$. To the best of our knowledge, it is unknown whether MO-A prevent the heart against I/R injury. In the present study, we found that MO-A significantly reduced myocardial apoptosis after I/R injury as revealed by the TUNEL assay in mice. To further investigate whether MO-A has a direct protective effect against I/R injury and to determine the possible mechanisms, we performed in vitro studies.

The results showed that MO-A inhibited apoptosis in H9C2 cardiomyocytes subjected to $\mathrm{H} / \mathrm{R}$ as evidenced by flow cytometry using Annexin V/PI staining. Additionally, MO-A upregulated Bcl-2 and downregulated Bax and cleaved caspase-3 protein expression levels in cultured $\mathrm{H} 9 \mathrm{C} 2$ cardiomyocytes. Therefore, as above, it was suggested that inhibiting apoptosis of cardiomyocytes was one of the important mechanisms by which MO-A exerted cardioprotective effects during myocardial I/R injury.

We further elucidated the molecular mechanisms by which MO-A exerts cardioprotective effects. Previous studies demonstrated that some signaling molecules were thought to serve as the upstream mediators of apoptosis during I/ $R$ injury ${ }^{[7,9]}$. The PI3K/Akt pathway is central to physical and pharmacological pre- and post-conditioning and salvaging the ischemia/reperfused myocardium ${ }^{[23-26]}$. It has been shown that Akt activation exerts beneficial effects on ischemic hearts ${ }^{[7,27,28]}$. In the present study, the phosphorylation levels of PI3K and Akt were 0.2-fold and 0.21-fold in the H/R group, respectively, compared with the control group. MO-A pretreatment resulted in a significant increase in the expression of both PI3K (8-fold) and p-Akt (4-fold). Furthermore, administration of the PI3K inhibitor wortmannin before MO-A treatment not only reduced the expression of p-Akt but also markedly decreased the Bcl-2/Bax ratio and increased active caspase-3 expression, which suggested that MO-A blocked $\mathrm{H} / \mathrm{R}$-induced myocardial apoptosis at least in part through PI3K-Akt activation.

It has been shown in previous studies that phosphorylation of eNOS by Akt with a subsequent increase in NO production was an important downstream effector in survival signaling in myocardial ischemia and reperfusion ${ }^{[29-31]}$. Our study also showed significantly increased p-eNOS expression (6.55-fold) and $\mathrm{NO}$ production in $\mathrm{H} / \mathrm{R}$ cardiomyocytes following MO-A treatment. More importantly, pretreatment with wortmannin significantly blocked the eNOS phosphorylation and NO increase induced by MO-A in H/R cardiomyocytes, suggesting that PI3K-Akt-eNOS-NO signaling may contribute to the MO-A-elicited cardioprotection and anti-apoptotic effect against $\mathrm{H} / \mathrm{R}$ injury in $\mathrm{H} 9 \mathrm{C} 2$ cardiomyocytes. Taken together, these data indicate that the PI3K-Akt-mediated anti-apoptotic effect may independently contribute to the cardioprotective effects of MO-A in myocardium suffering from I/R injury.

In summary, these results show that $\mathrm{MO}-\mathrm{A}$ exerts 
A
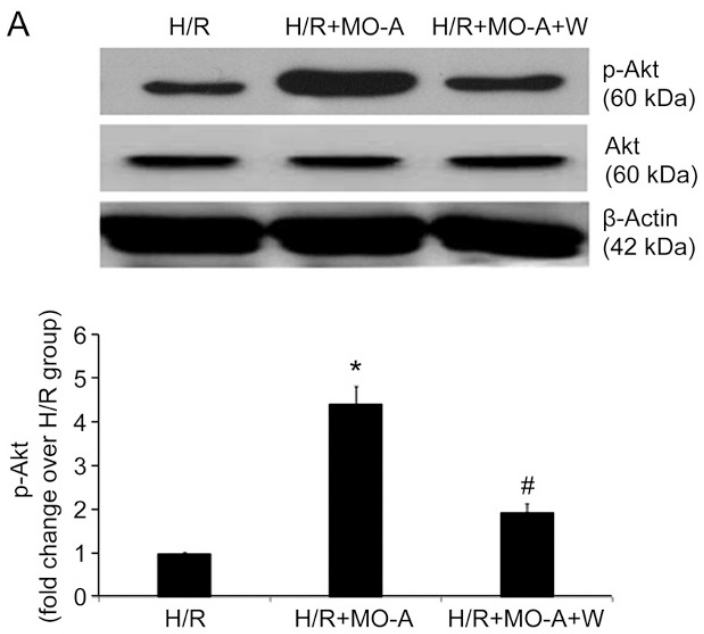

C
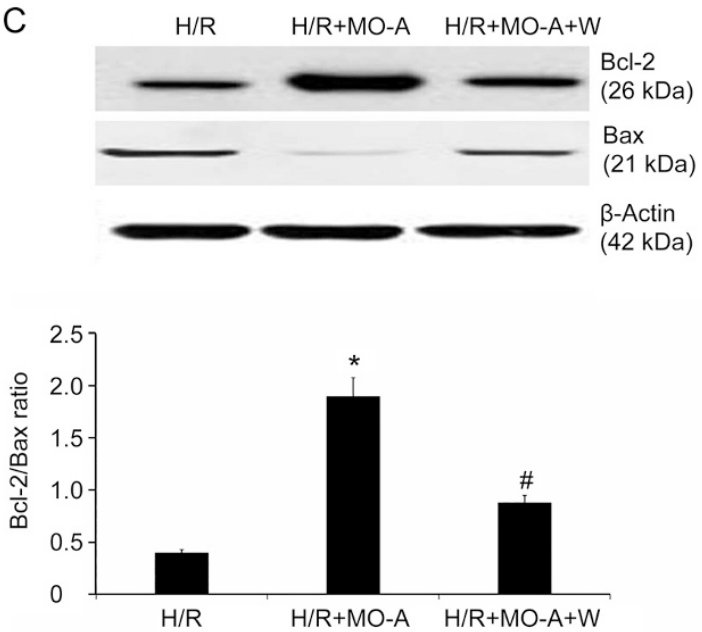

B
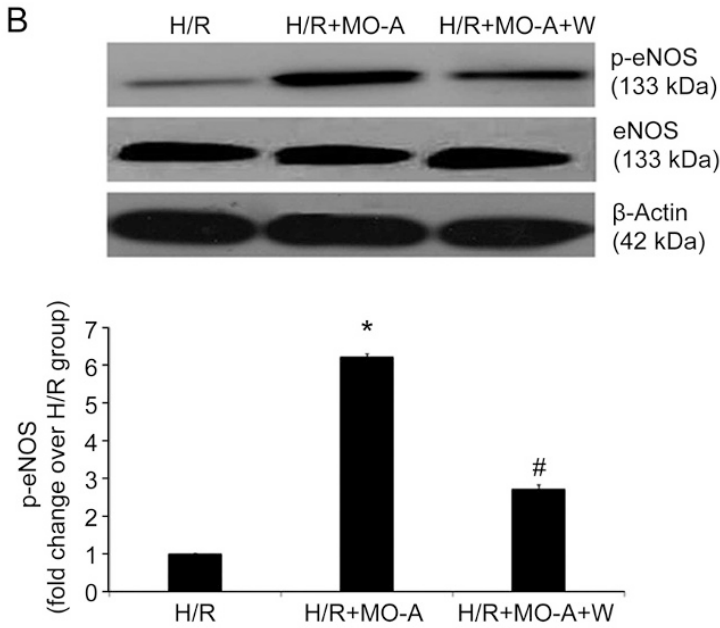

D
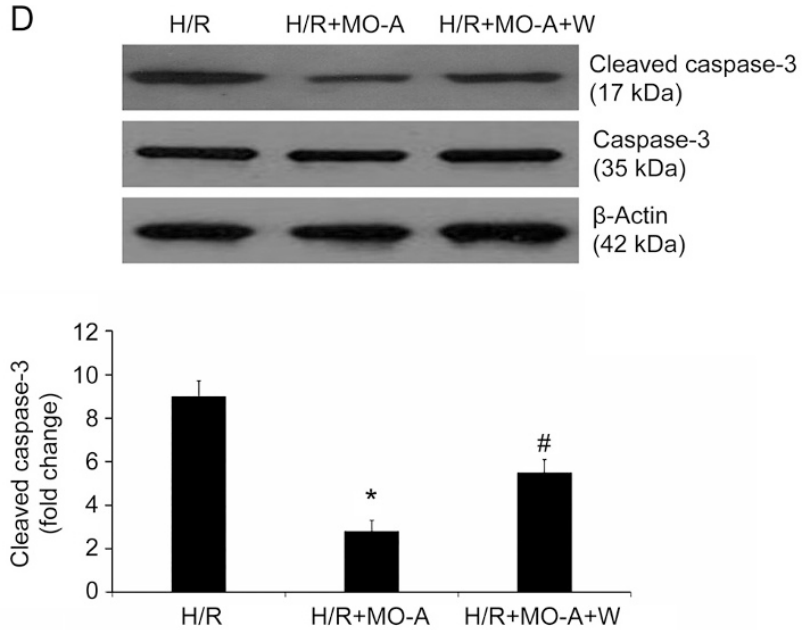

Figure 7. MO-A increased the $\mathrm{Bcl}-2 / \mathrm{Bax}$ ratio and decreased caspase-3 expression by activating the PI3K-Akt signaling pathway. (A-B) The expression levels of phosphorylated Akt and eNOS were reduced after H/R in $\mathrm{H} 9 \mathrm{C} 2$ cells when cells were co-treated with the PI3K/Akt inhibitor wortmannin. (C) The protein levels of $\mathrm{Bcl}-2$ and $\mathrm{Bax}$ and the ratio of Bcl-2/Bax. (D) The protein levels of cleaved caspase- 3 and the ratio of cleaved caspase-3/ $\beta$-actin. Values presented are mean \pm SEM. $n=6$ in each group. ${ }^{*} P<0.05$ vs H/R group. ${ }^{*} P<0.05$ vs H/R+MO-A group.

anti-apoptotic properties against myocardial I/R injury and improves cardiac functional recovery following reperfusion via activating the PI3K-Akt-eNOS signaling pathway. The findings suggest the potential therapeutic value of MO-A in the prevention and rescue of myocardial I/R injury.

The present study has some limitations. First, in the present study, we used the H9C2 cardiomyocytes to establish the in vitro $\mathrm{H} / \mathrm{R}$ model. However, the extent to which $\mathrm{H} 9 \mathrm{C} 2$ cells can accurately mimic the $\mathrm{H} / \mathrm{R}$ responses of primary cardiac myocytes has not yet been fully established. Second, in this experimental study, the animals are pre-treated with MO-A two weeks before $I / R$, which did not mimic the clinical setting. In daily practice, the time elapsed between the decision to revascularize and the procedure (angioplasty and CABG) is far less than two weeks. Therefore, the results of this study represent a novel target for alleviation of reperfusion injury and further studies are needed for the use of this strategy in clinical practice.

\section{Acknowledgments}

This work was supported by a clinical research fund from Anhui Medical University (2015xkj112) and the foundation of basic research program of Anhui University of Chinese Medicine (2016qn018).

\section{Author contribution}

Fei HE, Jing CHENG and Bang-long XU designed the experiments; Fei HE and Cai CHEN established and evaluated the in vivo I/R mouse model; Fei HE and Jian-long SHENG established and evaluated the in vitro $\mathrm{H} / \mathrm{R}$ injury model; Fei HE, Hong-jing JIA, Li HUANG, and Jing CHENG performed the cell viability assay, ROS and anti-oxidant analyses and Western blotting; Ji-xiong WU and Xiao-chen WANG completed the cardiac function analyses individually; and Fei HE and Jing CHENG analyzed the data and wrote the paper. 


\section{References}

1 Ibanez B, Heusch G, Ovize M, Van de Werf F. Evolving therapies for myocardial ischemia/reperfusion injury. J Am Coll Cardiol 2015; 65: 1454-71.

2 Yellon DM, Hausenloy DJ. Mechanisms of disease: myocardial reperfusion injury. New Engl J Med 2007; 357: 1121-35.

3 Heusch G. Molecular basis of cardioprotection: signal transduction in ischemic pre-, post-, and remote conditioning. Circ Res 2015; 116 : 674-99.

4 Hernandez-Resendiz S, Palma-Flores C, De Los Santos S, Roman-Anguiano NG, Flores M, de la Pena A, et al. Reduction of no-reflow and reperfusion injury with the synthetic 17 beta-aminoestrogen compound Prolame is associated with PI3K/Akt/eNOS signaling cascade. Basic Res Cardiol 2015; 110: 1.

5 Ma CJ, Li G, Zhang J, Zheng QS, Fan X, Wang ZH. An efficient combination of supercritical fluid extraction and high-speed countercurrent chromatography to extract and purify homoisoflavonoids from Ophiopogon japonicus (Thunb) Ker-Gawler. J Sep Sci 2009; 32: 1949-56.

6 Zhu YZ, Huang SH, Tan BKH, Sun J, Whiteman M, Zhu YC. Antioxidants in Chinese herbal medicines: a biochemical perspective. Nat Prod Rep 2004; 21: 478-89.

7 Hausenloy DJ, Yellon DM. New directions for protecting the heart against ischaemia-reperfusion injury: targeting the reperfusion injury Salvage kinase (RISK)-pathway. Cardiovasc Res 2004; 61: 448-60.

8 Tsang A, Hausenloy DJ, Mocanu MM, Yellon DM. Postconditioning: A form of "modified reperfusion" protects the myocardium by activating the phosphatidylinositol 3-kinase-Akt pathway. Circ Res 2004; 95: 230-2.

9 Zhao MM, Yang JY, Wang XB, Tang CS, Du JB, Jin HF. The PI3K/Akt pathway mediates the protection of $\mathrm{SO}(2)$ preconditioning against myocardial ischemia/reperfusion injury in rats. Acta Pharmacol Sin 2013; 34: 501-6.

10 Oyama J, Blais C, Liu XL, Pu MY, Kobzik L, Kelly RA, et al. Reduced myocardial ischemia-reperfusion injury in toll-like receptor 4-deficient mice. Circulation 2004; 109: 784-9.

11 Ren BH, Shen Y, Shao HT, Qian JJ, Wu HW, Jing H. Brain natriuretic peptide limits myocardial infarct size dependent of nitric oxide synthase in rats. Clin Chim Acta 2007; 377: 83-7.

12 Salas MA, Valverde CA, Sanchez G, Said M, Rodriguez JS, Portiansky $\mathrm{EL}$, et al. The signalling pathway of CaMKII-mediated apoptosis and necrosis in the ischemia/reperfusion injury. J Mol Cell Cardiol 2010; 48: 1298-306.

13 Elrod JW, Calvert JW, Morrison J, Doeller JE, Kraus DW, Tao L, et al. Hydrogen sulfide attenuates myocardial ischemia-reperfusion injury by preservation of mitochondrial function. Proc Natl Acad Sci U S A 2007; 104: 15560-5.

14 Zhou SS, He F, Chen AH, Hao PY, Song XD. Suppression of rat Frizzled-2 attenuates hypoxia/reoxygenation-induced $\mathrm{Ca}^{2+}$ accumulation in rat H9c2 cells. Exp Cell Res 2012; 318: 1480-91.

15 Lee S, Kim K, Kim YH, Chung MH, Kang I, Ha J, et al. Preventive role of propofol in hypoxia/reoxygenation-induced apoptotic H9c2 rat cardiac myoblast cell death. Mol Med Rep 2011; 4: 351-6.

16 Li LH, Wang JS, Kong LY. Protective effects of Shengmai San and its three fractions on cerebral ischemia-reperfusion injury. Chin J Nat Med 2013; 11: 222-30.

17 Li N, Zhang JY, Zeng KW, Zhang L, Che YY, Tu PF. Anti-inflammatory homoisoflavonoids from the tuberous roots of Ophiopogon japonicus.
Fitoterapia 2012; 83: 1042-5.

18 Chiong M, Wang ZV, Pedrozo Z, Cao DJ, Troncoso R, Ibacache M, et al. Cardiomyocyte death: mechanisms and translational implications. Cell Death Disease 2011; 2: 11.

19 Cheng Y, Zhu P, Yang J, Liu X, Dong S, Wang X, et al. Ischaemic preconditioning-regulated miR-21 protects heart against ischaemia/ reperfusion injury via anti-apoptosis through its target PDCD4. Cardiovasc Res 2010; 87: 431-9.

20 Wagner C, Tillack D, Simonis G, Strasser RH, Weinbrenner C. Ischemic post-conditioning reduces infarct size of the in vivo rat heart: role of PI3-K, mTOR, GSK-3beta, and apoptosis. Mol Cell Biochem 2010; 339: 135-47.

21 Aurora AB, Mahmoud AI, Luo X, Johnson BA, van Rooij E, Matsuzaki S, et al. MicroRNA-214 protects the mouse heart from ischemic injury by controlling $\mathrm{Ca}^{2+}$ overload and cell death. J Clin Invest 2012; 122: 1222-32.

22 Hullinger TG, Montgomery RL, Seto AG, Dickinson BA, Semus HM, Lynch JM, et al. Inhibition of miR-15 protects against cardiac ischemic injury. Circ Res 2012; 110: 71-81.

23 Arslan F, Lai RC, Smeets MB, Akeroyd L, Choo A, Aguor ENE, et al. Mesenchymal stem cell-derived exosomes increase ATP levels, decrease oxidative stress and activate PI3K/Akt pathway to enhance myocardial viability and prevent adverse remodeling after myocardial ischemia/reperfusion injury. Stem Cell Res 2013; 10: 301-12.

24 Breivik L, Helgeland E, Aarnes EK, Mrdalj J, Jonassen AK. Remote postconditioning by humoral factors in effluent from ischemic preconditioned rat hearts is mediated via PI3K/Akt-dependent cellsurvival signaling at reperfusion. Basic Res Cardiol 2011; 106 : 135-45.

25 Takada Y, Hashimoto M, Kasahara J, Aihara K, Fukunaga K. Cytoprotective effect of sodium orthovanadate on ischemia/reperfusioninduced injury in the rat heart involves Akt activation and inhibition of fodrin breakdown and apoptosis. J Pharmacol Exp Ther 2004; 311: 1249-55.

26 Wu H, Ye M, Yang J, Ding J, Yang J, Dong W, et al. Nicorandil protects the heart from Ischemia/reperfusion injury by attenuating endoplasmic reticulum response-induced apoptosis through PI3K/Akt signaling pathway. Cell Physiol Biochem 2015; 35: 2320-32.

27 Uchiyama T, Engelman RM, Maulik N, Das DK. Role of Akt signaling in mitochondrial survival pathway triggered by hypoxic preconditioning. Circulation 2004; 109: 3042-9.

28 Bharti S, Golechha M, Kumari S, Siddiqui KM, Arya DS. Akt/GSK3beta/eNOS phosphorylation arbitrates safranal-induced myocardial protection against ischemia-reperfusion injury in rats. Eur J Nutr 2012; 51: 719-27.

29 Wang T, Mao X, Li H, Qiao S, Xu A, Wang J, et al. N-Acetylcysteine and allopurinol up-regulated the Jak/STAT3 and PI3K/Akt pathways via adiponectin and attenuated myocardial postischemic injury in diabetes. Free Radical Biol Med 2013; 63: 291-303.

30 Gao F, Gao E, Yue TL, Ohlstein EH, Lopez BL, Christopher TA, et al. Nitric oxide mediates the antiapoptotic effect of insulin in myocardial ischemia-reperfusion: the roles of PI3-kinase, Akt, and endothelial nitric oxide synthase phosphorylation. Circulation 2002; 105: $1497-$ 502.

31 Peng X, Chen R, Wu Y, Huang B, Tang C, Chen J, et al. PPARgamma$\mathrm{PI}$ KK/AKT-NO signal pathway is involved in cardiomyocyte hypertrophy induced by high glucose and insulin. J Diabetes Complication 2015; 29: $755-60$. 